\title{
Erratum to: Empowerment and its Associations in Schizophrenia: A Cross-sectional Study
}

\author{
Amlan Kusum Jana • Daya Ram • \\ Samir Kumar Praharaj
}

Published online: 6 June 2014

(C) Springer Science+Business Media New York 2014

Erratum to: Community Ment Health J

DOI 10.1007/s10597-014-9729-4

Authors' affiliations are incorrectly linked in the original publication, this erratum is intended to correct the error.

The online version of the original article can be found under doi:10.1007/s10597-014-9729-4.

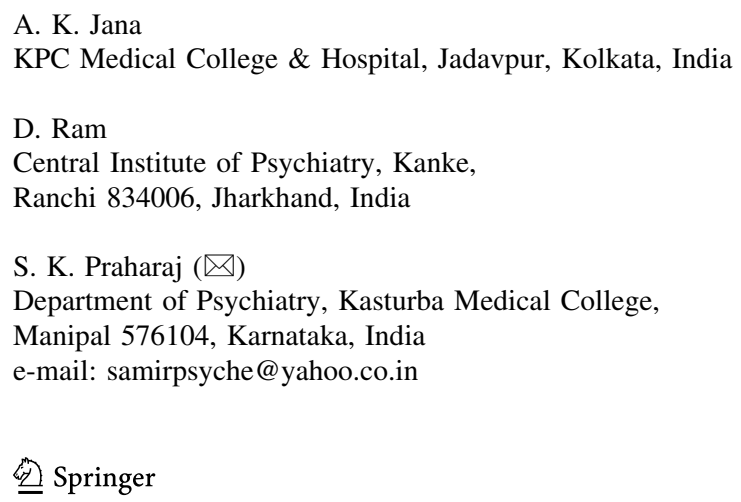

